\title{
Microscopic Mechanism of Cement Improving the Strength of Lime-Fly Ash-Stabilized Yellow River Alluvial Silt
}

\author{
Xiaobin Zhang $\mathbb{D}^{1,2}$ and Zhiduo Zhu $\mathbb{D}^{1,2}$ \\ ${ }^{1}$ School of Transportation, Southeast University, Nanjing 211189, China \\ ${ }^{2}$ Jiangsu Key Laboratory of Urban Underground Engineering \& Environmental Safety, Southeast University, \\ Nanjing 211189, China \\ Correspondence should be addressed to Zhiduo Zhu; zhuzhiduo@seu.edu.cn
}

Received 23 October 2019; Revised 27 April 2020; Accepted 16 November 2020; Published 10 December 2020

Academic Editor: Yingchun Li

Copyright (c) 2020 Xiaobin Zhang and Zhiduo Zhu. This is an open access article distributed under the Creative Commons Attribution License, which permits unrestricted use, distribution, and reproduction in any medium, provided the original work is properly cited.

\begin{abstract}
Silt is a kind of soil with poor engineering performance. Lime-fly ash- (LF-) stabilized silt has the problem of low early strength. In this study, it is aimed to investigate the effect of cement on improving the strength of LF-stabilized silt and reveal the microscopic mechanism. A fixed percentage of LF (18\%) plus different percentages of cement $(0 \%, 2 \%, 4 \%$, and $6 \%)$ were mixed with Yellow River alluvial silt (YRAS). Soil samples for tests were artificially made by compaction in the laboratory. Unconfined compressive strength (UCS) tests were performed on soil samples cured for $7 \mathrm{~d}, 28 \mathrm{~d}, 60 \mathrm{~d}$, and $90 \mathrm{~d}$. Scanning electron microscope (SEM) tests, energy dispersive X-ray spectroscopy (EDS) tests, and mercury intrusion porosimetry (MIP) tests were performed on soil samples cured for $7 \mathrm{~d}$ and $28 \mathrm{~d}$. UCS results showed that the early strength of LF-stabilized YRAS developed significantly after adding cement. UCS also increased with the increase in cement content and curing time. SEM results revealed the differences in microstructure of LF-stabilized YRAS before and after adding cement. Before adding cement, the main microstructure characteristics included small soil particles, large number of pores, and loose particle arrangement. After adding cement, the main microstructure characteristics included large bonded particles, small number of pores, and dense particle arrangement. The EDS results showed that, after curing for $28 \mathrm{~d}$, the elements of gels in stabilized YRAS had changed, mainly including appearance of $\mathrm{C}$ and a significant increase of Ca. MIP results showed that the pores with a size of $1 \mu \mathrm{m} \sim 10 \mu \mathrm{m}$ accounted for the largest proportion in stabilized YRAS. The product (mainly C-S-H) of cement hydration mainly filled the pores with a size larger than $10 \mu \mathrm{m}$ at the early stage. Combining strength results and microresults, the micromechanism of cement improving the strength of LF-stabilized YRAS was discussed.
\end{abstract}

\section{Introduction}

Silt is a fine-grained soil or the fine-grained portion of soil, with a plasticity index less than 4 or if the plot of plasticity index versus liquid limit falls below the "A" line [1]. Silt can be seen in many areas of China, such as Jiangsu, Anhui, Hubei, Henan, Shandong, Shanxi, and many other provinces. Silt from different areas may have different engineering characteristics. Much silt can be seen in the Ancient Yellow River district of Jiangsu Province, China. Silt from this area is the product of alluvial action of the Yellow River. So, it is called the Yellow River alluvial silt (abbreviated as YRAS). This type of soil has poor engineering properties. It is difficult to compact in dry conditions, and it is easily liquefied under dynamic load. In addition, it has the disadvantages of low strength and low stiffness. Without effective treatment, this soil as a foundation may cause many problems, such as uneven settlement, excessive lateral deformation, and building instability [2].

There are many ways to improve the engineering properties of soil, in which stabilization is economical, fast, and efficient. Soil stabilization means improving the engineering properties of soil by adding curing agent. After adding the curing agent into the soil, complex physical and chemical actions will occur in the mixture of soil and curing agent. Because of its good effect, soil stabilization has been 
widely used in civil engineering [3-11]. After stabilization, many engineering properties of soil can be improved. $\mathrm{Pu}$ et al. [7] carried out mechanical tests on silt stabilized by lime, lime-cement, and SEU-2 binder and found that adding curing agent could effetely improve the unconfined compressive strength and water stability of silt. Pu et al. [12] also conducted one-dimensional consolidation tests and consolidated undrained triaxial compression tests on silt stabilized by SEU-2 binder and revealed that the deformation properties and shear strength had been greatly improved after stabilization. The study of Wang et al. [13] also showed that cement and lime stabilization improved the undrained shear strength of sediment from Dunkirk Port in France. Dispersive and expansive soils could cause serious problems for many engineering structures. To solve this problem, Türköz et al. [14, 15] innovatively used cement-natural zeolite mixtures and silica fume-lime mixtures to stabilize clay soil with dispersive and swell properties, respectively. A series of tests including swell percentage, swell pressure, crumb, pinhole, unconfined compressive strength, and unconsolidated-undrained triaxial compression tests were performed on stabilized clay soil. The results showed that cement-natural zeolite mixtures and silica fume-lime mixtures can not only significantly improve swell and dispersive characteristics of soil but also effectively increase the strength. Soil structure has a great influence on soil engineering performance, especially for undisturbed soil and stabilized soil. Wang et al. [16] studied the influence of cement/lime on the nonlinear stress-strain behaviour with relation to the constrained modulus. The study showed that cement and lime were important for the strength development of soil, and they could increase the compression index of soil. Similar conclusions were obtained in the study of the one-dimensional compression behaviour of cement-lime-stabilized soft clay [17]. In a word, stabilization can effectively improve the engineering performance of soil.

Traditional curing agents used for soil stabilization mainly include cement $[13,18,19]$, lime $[20,21]$, and other calcium-based curing materials. Some new curing materials may also have a good curing effect. For example, carbonated reactive magnesia has a good ability to stabilize silt [22, 23]. For some special soil, a curing agent alone does not work well. The mixtures of industrial by-products and cement/ lime may have a better curing effect and be more economical. The mixtures used include cement-fly ash $[5,24]$, cement-lime [7, 25], cement-zeolite [15], and silica fumelime [14]. As a kind of stabilizer, the mixture of lime and fly ash has the advantages of low cost, easy construction, and good stabilizing effect, and so it has been widely used in road engineering [26-29]. At present, some scholars have conducted relevant research on the engineering characteristics of lime-fly ash-stabilized silt. The study shows that lime-fly ash-stabilized silt has the advantages of high late strength, good integrity, high resistance to bending, and high modulus $[30,31]$. In view of the great engineering properties, lime-fly ash-stabilized YRAS (abbreviated as LF-YRAS) was originally intended to be used as subbase of a highway in Jiangsu Province of China. Preliminary tests showed that LF-YRAS has the advantages of good integrity and high late strength, but it also has the disadvantage of low early strength, which may affect construction progress. In order to improve the early strength of LF-YRAS, cement was chosen as an additional additive because of its characteristics of rapid hydration, short setting time, and high early strength $[15,32,33]$.

The macroscopic mechanical properties of soil essentially depend on its microstructure, so studying soil microstructure characteristics helps to better understand the mechanism of strength improvement [34,35]. Some scholars have used different microscopic methods to study the microstructure characteristics of soil or stabilized soil, including scanning electron microscopy (SEM) [36-40], mercury intrusion porosimetry (MIP) [41-43], energy dispersive X-ray spectroscopy (EDS) [44-46], and X-ray diffraction $[25,47]$. Using microscopic technology to study soil microscopic properties has become quite popular and mature. In this study, three kinds of microscopic methods, i.e., SEM, EDS, and MIP were used to explore the microscopic properties of stabilized YRAS.

In short, in this study, unconfined compression strength (UCS) tests, SEM tests, EDS tests, and MIP tests were carried out on stabilized silt samples. Based on the results of UCS tests, the effects of cement on improving the early strength of LF-YRAS will be explored, and the influence of additive amount and curing age on strength will be studied. Based on the results of SEM, EDS, and MIP tests, the microstructure, element composition, and pore characteristics of LF-YRAS before and after adding cement will be compared. Finally, the microscopic mechanism of cement improving the strength of LF-YRAS will be discussed.

\section{Materials and Methods}

2.1. Test Materials. For the tested soil samples were artificially made in the laboratory, disturbed soil was collected by using a simple shovel in the shallow layer (about $0.5 \mathrm{~m}$ deep) from the waste Yellow River district in the northern part of Jiangsu Province, China. The specific location is $34^{\circ} 04^{\prime} \mathrm{N}$ and $119^{\circ} 48^{\prime} \mathrm{E}$ as shown in Figure 1.

Soil grain size distribution measured using a laser particle size analyzer is shown in Figure 2. It can be seen from Figure 2 that the contents of clay-size $(<5 \mu \mathrm{m})$ particles, siltsize $(5 \sim 75 \mu \mathrm{m})$ particles, and sand-size $(>75 \mu \mathrm{m})$ particles are $8.78 \%, 58.79 \%$, and $32.43 \%$, respectively.

The basic physical properties of soil are shown in Table 1. Soil chemical composition measured using an X-ray fluorescence spectrometer is shown in Table 2. It can be seen from Table 2 that the main chemical components of soil are $\mathrm{SiO}_{2}, \mathrm{Al}_{2} \mathrm{O}_{3}$, and $\mathrm{Fe}_{2} \mathrm{O}_{3}$, accounting for $91.37 \%$ of the total. According to the technical specification of Test Methods of Soils for Highway Engineering (JTG E40-2007) [48] of China, the tested soil is classified as low liquid limit silt (ML). Same classification is obtained according to ASTM D2487-17e1 [1].

The lime used in the test was purchased from Nanjing City of China, and it was pale and powdery. According to the technical specification of Test Methods of Materials 


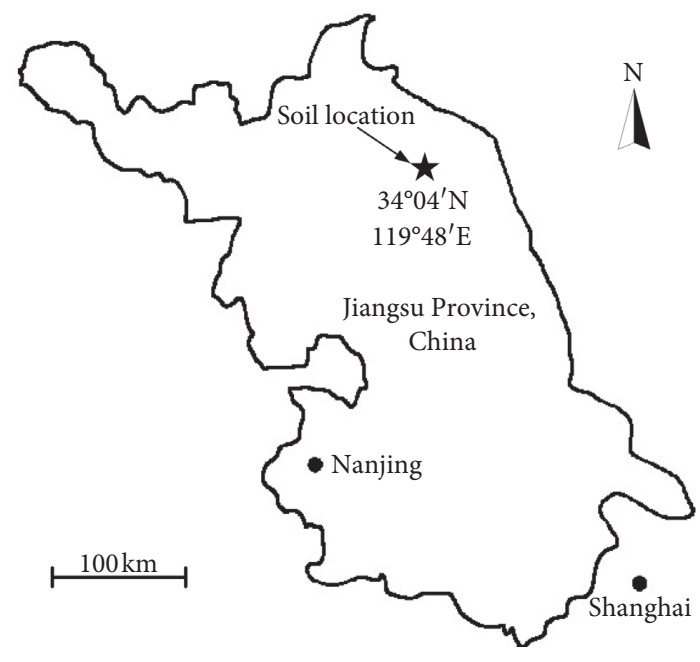

Figure 1: The specific location of test soil.

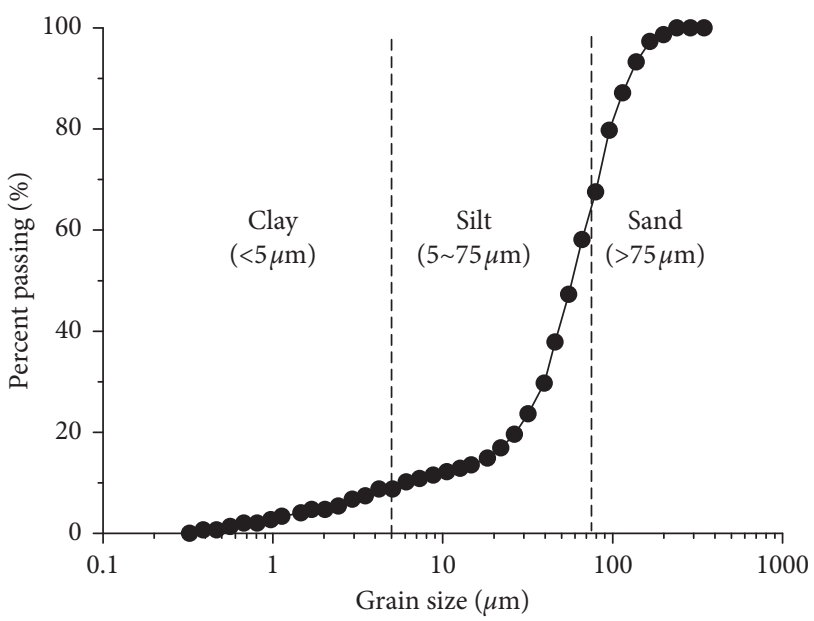

Figure 2: The grain size distribution of test soil.

TABLE 1: The basic physical properties of test soil.

\begin{tabular}{lc}
\hline Property & Value \\
\hline Water content $(\%)$ & 27 \\
Density $\left(\mathrm{g} / \mathrm{cm}^{3}\right)$ & 1.97 \\
Specific gravity & 2.7 \\
Void ratio & 0.779 \\
Liquid limit $(\%)$ & 27.18 \\
Plastic limit $(\%)$ & 21.51 \\
Plastic index & 5.67 \\
Maximum dry density $\left(\mathrm{g} / \mathrm{cm}^{3}\right)$ & 1.72 \\
Optimum water content $(\%)$ & 16.5 \\
\hline
\end{tabular}

Stabilized with Inorganic Binders for Highway Engineering (JTG E51-2009) [49] of China, the lime was tested, and the results showed that the content of active calcium and magnesium in lime was $71.87 \%$.

The fly ash used in the test was produced in Zhenjiang City of China, and it was gray-black and powdery. Likewise, according to the technical specification of Test Methods of Materials Stabilized with Inorganic Binders for Highway
TABLE 2: The chemical composition of test soil.

\begin{tabular}{lc}
\hline Composition & Content (\%) \\
\hline $\mathrm{SiO}_{2}$ & 74.64 \\
$\mathrm{Al}_{2} \mathrm{O}_{3}$ & 10.2 \\
$\mathrm{Fe}_{2} \mathrm{O}_{3}$ & 6.53 \\
$\mathrm{TiO}_{2}$ & 0.54 \\
$\mathrm{CaO}$ & 0.63 \\
$\mathrm{MgO}$ & 0.74 \\
$\mathrm{~K}_{2} \mathrm{O}$ & 1.44 \\
$\mathrm{Na}_{2} \mathrm{O}$ & 0.57 \\
$\mathrm{P}_{2} \mathrm{O}_{3}$ & 0.068 \\
$\mathrm{SO}_{3}$ & 0.022 \\
Loss on ignition & 0.52 \\
Organic matter & 4.1 \\
\hline
\end{tabular}

Engineering (JTG E51-2009) [49], the fly ash was tested, and the results showed that the total content of $\mathrm{SiO}_{2}, \mathrm{Fe}_{2} \mathrm{O}_{3}$, and $\mathrm{Al}_{2} \mathrm{O}_{3}$ was $79.16 \%$. The content of $\mathrm{CaO}$ in fly ash was $0.64 \%$. The loss on ignition of fly ash was $7.79 \%$. The specific surface area of fly ash was $2520 \mathrm{~cm}^{2} / \mathrm{g}$.

The cement used in the test was ordinary Portland cement P.O32.5 purchased from Nanjing City of China. The cement was off-white and powdery. According to the technical specification of Portland Cement for Road (GB 13693-2005) [50] of China, the cement was tested, and the results showed that the main components of cement were $\mathrm{CaO}$ (55.37\%), $\mathrm{SiO}_{2}$ (25.41\%), and $\mathrm{Al}_{2} \mathrm{O}_{3}$ (10.09\%). The initial setting time and final setting time of the cement were $205 \mathrm{~min}$ and $260 \mathrm{~min}$, respectively.

2.2. Test Scheme. The test scheme is shown in Table 3. As shown in Table 3, the content of lime + fly ash is fixed at $18 \%$ (6\% lime and $12 \%$ fly ash), and the content of cement is $2 \%$, $4 \%$, and 6\%. For brevity, in Table 3, C2, C4, and C6 represent the soil added with $2 \%, 4 \%$, and $6 \%$ cement, respectively.

According to the test plan in Table 3, standard compaction tests were firstly performed on YRAS, LF-YRAS, C2, $\mathrm{C} 4$, and $\mathrm{C} 6$ in accordance with the procedure in Test Methods of Soils for Highway Engineering (JTG E40-2007) [48]. The test results are shown in Table 4. During compaction tests, the diameter of the hammer was $5 \mathrm{~cm}$. The mass of the hammer was $2.5 \mathrm{~kg}$. The drop height was $30 \mathrm{~cm}$. A test tube with a diameter of $10 \mathrm{~cm}$ and a height of $12.7 \mathrm{~cm}$ was used. The soil was filled in 3 layers, and the number of hammering per layer was 27 . The energy density of hammering was $598.2\left(\mathrm{~kJ} / \mathrm{m}^{3}\right)$.

2.3. Test Methods. Soil samples for UCS tests were artificially made in the laboratory. The method of making samples was strictly in accordance with the Chinese specification of Test Methods of Soils for Highway Engineering (JTG E40-2007) [48]. First of all, according to the test plan in Table 3, silt and additive (lime-fly ash or cement-lime-fly ash) were mixed and stirred uniformly in a small mixer. Secondly, referring to the compaction test results in Table 4, optimal amount (by dry weight of silt-additive mixture) of distilled water was added to the soil. The water contents were $18.9 \%, 18.0 \%$, 
TABLe 3: Test scheme.

\begin{tabular}{|c|c|c|c|c|c|}
\hline Tests & Additives & Content (\%) & Abbreviation & Curing time $(\mathrm{d})$ & Curing conditions \\
\hline \multirow{4}{*}{ UCS } & Lime + fly ash & $6+12$ & LF-YRAS & \multirow{4}{*}{$7,28,60,90$} & \multirow{4}{*}{$\begin{array}{l}\text { Standard curing } \\
\text { Curing in water }\end{array}$} \\
\hline & Cement + lime + fly ash & $2+6+12$ & $\mathrm{C} 2$ & & \\
\hline & Cement + lime + fly ash & $4+6+12$ & $\mathrm{C} 4$ & & \\
\hline & Cement + lime + fly ash & $6+6+12$ & $\mathrm{C} 6$ & & \\
\hline SEM, EDS, and MIP & $\begin{array}{c}\text { Lime + fly ash } \\
\text { Cement + lime + fly ash }\end{array}$ & $\begin{array}{c}6+12 \\
2+6+12\end{array}$ & $\begin{array}{l}\text { LF-YRAS } \\
\text { C2 }\end{array}$ & 7,28 & Standard curing \\
\hline
\end{tabular}

TABLe 4: Compaction test results of soil.

\begin{tabular}{lcccc}
\hline Soil & Additives & Content $(\%)$ & Maximum dry density $\left(\mathrm{g} / \mathrm{cm}^{3}\right)$ & Optimum water content $(\%)$ \\
\hline YRAS & - & - & 1.72 & 16.5 \\
LF-YRAS & Lime + fly ash & $6+12$ & 1.611 & 18.9 \\
C2 & Cement + lime + fly ash & $2+6+12$ & 1.627 & 18.0 \\
C4 & Cement + lime + fly ash & $4+6+12$ & 1.631 & 17.7 \\
C6 & Cement + lime + fly ash & $6+6+12$ & 1.633 & 17.5 \\
\hline
\end{tabular}

$17.7 \%$, and $17.5 \%$ for LF-YRAS, C2, C4, and C6, respectively. After adding water, the soil was stirred again until completely homogeneous. And then, the wetted soil was immediately put into the sample maker and compacted. In order to be consistent with practical engineering, the degree of compaction was $96 \%$ by controlling sample weight. After compaction, a cylindrical sample with a diameter of $5 \mathrm{~cm}$ and a height of $10 \mathrm{~cm}$ was made. A study showed that delayed compaction had a significant effect on the strength of lime-stabilized clay soil [51]. In order to avoid the effect of delayed compaction, in this study, every sample was made within one hour after adding water. Next, the sample was sealed in a plastic bag and placed in a standard curing room (temperature $20 \pm 3^{\circ} \mathrm{C}$ and relative humidity $\geq 95 \%$ ) for curing. Temperature is a key factor affecting the speed of soil stabilization [52], so the curing temperature was the same and consistent for all samples. For standard curing, the curing time was $7 \mathrm{~d}, 28 \mathrm{~d}, 60 \mathrm{~d}$, and $90 \mathrm{~d}$, respectively. However, for water curing, the soil samples were first cured for $3 \mathrm{~d}, 7 \mathrm{~d}, 7 \mathrm{~d}$, and $7 \mathrm{~d}$ under the same conditions as the standard curing and then placed in water for $4 \mathrm{~d}, 21 \mathrm{~d}, 53 \mathrm{~d}$, and $83 \mathrm{~d}$, respectively. Finally, after curing, the UCS tests were performed on the samples with a strain-controlled UCS tester named YSH-2. The testing procedure was also strictly in accordance with Chinese Test Methods of Soils for Highway Engineering (JTG E40-2007) [48]. The compression rate was fixed as $1 \% / \mathrm{min}$ during the test.

For SEM, EDS, and MIP tests, the sample preparation was the same as the UCS test. SEM tests were carried out according to the procedure in General Rules for Measurement of Length in Micron Scale by SEM (GB/T 16594-2008) [53]. First of all, the sample for the SEM test was carefully broken into small pieces, in which a small piece (about $1 \mathrm{~cm}^{3}$ ) with a clear section was selected. The clear section should not be disturbed before testing. Secondly, the small piece was rapidly frozen in liquid nitrogen $\left(-190^{\circ} \mathrm{C}\right)$ and then placed in a vacuum freeze-drying apparatus named XIANOU-18N for $24 \mathrm{~h}$. Next, the small dry piece was plated with a thin layer of carbon to improve conductivity. Finally,
SEM tests were performed on the small piece using Scanning Electron Microscopy S-3000N, which was produced by Hitachi Company of Japan.

The EDS tests and SEM tests were performed simultaneously. In SEM views, some points (also called microareas) that can reflect the typical morphology of sample microstructure were selected, and then, the EDS tests were performed on these points one by one. By detecting and analyzing the characteristic X-rays from these points, the types and contents of the element could be obtained in EDS. The EDS tests were carried out in accordance with the procedures in Microbeam Analysis-Quantitative Analysis using Energy Dispersive Spectrometry (GB/T 17359-2012) [54].

Except for plating a thin layer of conductive material on the surface, sample preparation for MIP tests was the same as that for SEM tests. After freeze-drying, MIP tests were directly performed on the dried samples using an automatic mercury porosimeter called AutoPore IV9500 that was produced by Micromeritics Instruments Corporation. The tests were carried out in strict accordance with the procedures in Pore Size Distribution and Porosity of Solid Materials by Mercury Porosimetry and Gas Adsorption-Part 1: Mercury Porosimetry (GB/T 21650.1-2008) [55].

\section{Results and Discussion}

3.1. UCS Test. The UCS test results are shown in Figure 3. It can be seen from Figure 3 that LF-YRAS has low early UCS. The UCS only reaches $73.5 \mathrm{kPa}$ after $7 \mathrm{~d}$ standard curing and $224.2 \mathrm{kPa}$ after $28 \mathrm{~d}$ standard curing, which does not meet the requirements for subsequent construction. It can also be seen from Figure 3 that with the increase of curing time, UCS increases, and adding cement can effectively improve the UCS of LF-YRAS, especially at the early stage. By adding $4 \%$ cement, the UCS of LF-YRAS increases to $285.2 \mathrm{kPa}(7 \mathrm{~d}$ standard curing) and $575.3 \mathrm{kPa}$ ( $28 \mathrm{~d}$ standard curing), which meets the requirements for subsequent construction. In addition, it can be found that adding cement can improve 


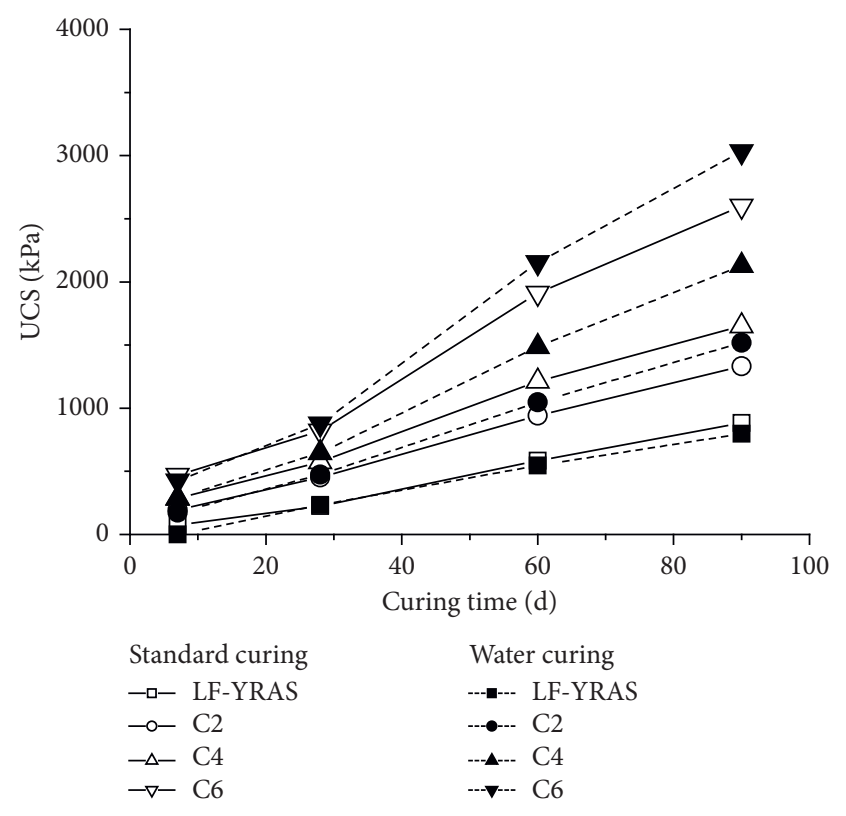

FIGURE 3: UCS test results of LF-YRAS, C2, C4, and C6 after curing for $7 \mathrm{~d}, 28 \mathrm{~d}, 60 \mathrm{~d}$, and $90 \mathrm{~d}$.

the water stability of LF-YRAS. For LF-YRAS, the UCS of the water curing sample is lower than that of the standard curing sample, while after adding cement, the situation is reversed.

In order to further reflect cement contribution to improve the UCS of LF-YRAS at different curing stages, the term "UCS growth rate" is introduced. UCS growth rate refers to the ratio of net strength increase after adding cement to the strength before adding cement of LF-YRAS. In brief, the physical implication of this term is net strength increase (\%) of LF-YRLS after adding cement, and this term is helpful to clearly see how much cement has contributed to strength increase and at which curing stage the cement is more effective. UCS growth rates at different curing times are shown in Figure 4. Figure 4 shows that the UCS growth rates have higher values at the early stage (curing for $7 \mathrm{~d}$ ) and then gradually decrease as curing time increases, and finally, they tend to be stable after $28 \mathrm{~d}$ curing. This means that cement is more effective for the early strength development of LF-YRAS.

Many scholars have studied the relationship between strength and curing time of stabilized soil. Horpibulsuk et al. [18] proposed the relationship between UCS and curing time of cement-stabilized soil. The relationship is as follows:

$$
\frac{\mathrm{UCS}_{t}}{\mathrm{UCS}_{28 \mathrm{~d}}}=A+B \ln t
$$

where $t$ is curing time (days), $A$ is a constant, $B$ is coefficient, $\mathrm{UCS}_{t}$ is the UCS of stabilized soil after curing for $t$, and $\mathrm{UCS}_{28 \mathrm{~d}}$ is the UCS of stabilized soil after curing for $28 \mathrm{~d}$.

Referring to the method of Horpibulsuk, the UCS of stabilized YRAS is normalized similarly in this study. The normalized result is shown in Figure 5. From Figure 5, it can be seen that the correlation between normalized UCS and

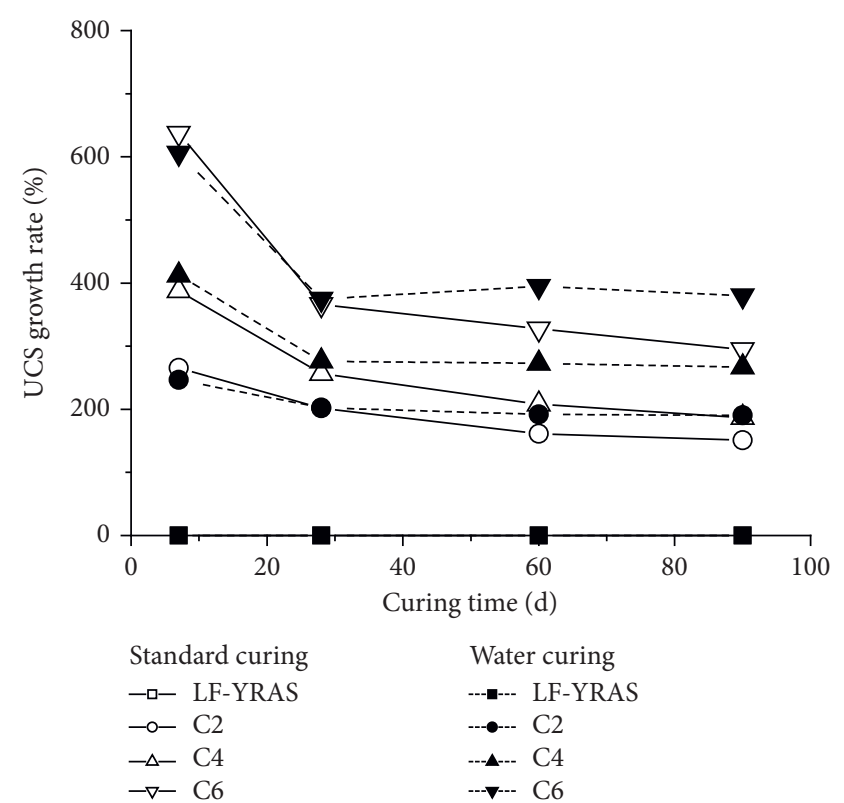

FIgURE 4: UCS growth rates of LF-YRAS, C2, C4, and C6 after curing for $7 \mathrm{~d}, 28 \mathrm{~d}, 60 \mathrm{~d}$, and $90 \mathrm{~d}$.

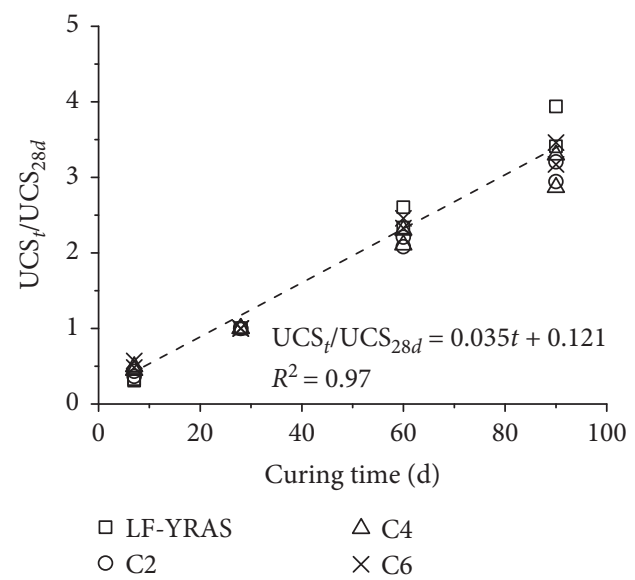

FIgURE 5: The ratio of $\mathrm{UCS}_{t}$ to $\mathrm{UCS}_{28 \mathrm{~d}}$ of LF-YRAS, C2, C4, and C6 after curing for $7 \mathrm{~d}, 28 \mathrm{~d}, 60 \mathrm{~d}$, and $90 \mathrm{~d}$.

curing time is quite good $\left(R^{2}=0.97\right)$. The fitting relationship between normalized UCS and curing time is as follows:

$$
\frac{\mathrm{UCS}_{t}}{\mathrm{UCS}_{28 \mathrm{~d}}}=0.035 t+0.121
$$

where $t$ is curing time (days), $\mathrm{UCS}_{t}$ is the UCS of stabilized YRAS after curing for $t$, and $\mathrm{UCS}_{28 \mathrm{~d}}$ is the UCS of stabilized YRAS after curing for $28 \mathrm{~d}$.

It can be seen from equation (1) that, when curing time $t$ is equal to 0 , the equation has no meaning. This means the soil samples that have just been made have infinitely low negative strength, which is inconsistent with the actual situation. Unlike equation 1, equation 2 has no such defect. In equation (2), the relationship between normalized UCS and curing time is linear, and the equation has meaning at 
the point of $t=0$. According to equation (2), once the UCS of $28 \mathrm{~d}$ curing is known, the UCS of other curing times can be predicted, which has a practical value for optimizing YRAS stabilization design and shortening the construction period. It can be inferred from the difference between equations (1) and (2) that these two equations are not universal for all stabilized soils. Equation (1) is for high water content clay stabilized by cement, while equation (2) is for silt stabilized by a mixture of cement, lime, and fly ash. Different stabilized soil may have different equations. Whether equation (2) can be applied to other types of soil still needs further study.

3.2. SEM Test. SEM test results are shown in Figure 6, in which Figure 6(a) shows the SEM views of LF-YRAS and Figure 6(b) shows the SEM views of C2. As marked in Figures 6(a) and 6(b), the bright parts represent soil particles and the dark parts represent pores between particles. From Figure 6(a), some obvious microstructure features of LFYRAS can be seen. First, it can be seen that the sizes of soil particles are quite small (mainly $10 \mu \mathrm{m} \sim 100 \mu \mathrm{m}$ ). This size distribution is nearly consistent with silt in Figure 2, in which silt-size $(5 \sim 75 \mu \mathrm{m})$ particles account for $58.79 \%$. Second, by comparing with Figure 6(b), it can be seen that there are more and larger pores in LF-YRAS. Considering the same sample preparation, the reason for more and larger pores is that there are few gels to coat soil particles and fill pores. Third, it can be seen that the arrangement of soil particles is quite loose. There are few connections between soil particles, leading to unstable microstructure. Once loaded, the soil particles are easier to turn and slide, which is macroscopically low in strength. In summary, the main microstructure features of LF-YRAS include small soil particles, large number of pores, and loose particle arrangement.

The reason why LF-YRAS has such microstructure features is that there are few gels. At this early stage, the hydration reaction of $\mathrm{CaO}$, ion exchange reaction of $\mathrm{Ca}^{2+}$, and crystallization reaction of $\mathrm{Ca}(\mathrm{OH})_{2}$ proceed slowly, which produces small amounts of gels such as $\mathrm{Ca}(\mathrm{OH})_{2}$ and $\mathrm{Ca}(\mathrm{OH})_{2} \bullet \mathrm{nH}_{2} \mathrm{O}$. In addition, carbonation reaction of $\mathrm{Ca}$ $(\mathrm{OH})_{2}$ and pozzolanic reaction proceed much more slowly, so not enough gels are produced at this stage. For stabilized soil, the quantity and strength of gels are the most important factors for improving soil strength, so few gels mean low strength.

From Figure 6(b), some microstructure features of C2 can be seen. First, it can be seen that the particles in C2 are coated and bonded by gels, which are quite different from LF-YRAS. The coated and bonded particles have larger sizes. Second, it can be seen that compared with LF-YRAS, C2 has fewer and smaller pores. The reason is that many gels have filled the pores between particles. Third, it can be seen that the arrangement of soil particles is very dense. Because of the coating, bonding, and filling of gels, $\mathrm{C} 2$ has a stable microstructure, and the particles are not easy to turn and slide when subjected to load, which is macroscopically high in strength. In summary, after adding $2 \%$ cement to LF-YRAS, the changes of microstructure mainly include large bonded particles, small number of pores, and dense particle arrangement. The reason why $\mathrm{C} 2$ has such microstructure changes is that the hydration of cement is fast. Many gels (mainly $\mathrm{CaO} \bullet \mathrm{SiO}_{2} \bullet \mathrm{YH}_{2} \mathrm{O}$ ) are produced from cement hydration at this early curing stage [15]. The gels coat soil particles, bond soil particles, and fill pores between soil particles, which change the microstructure and improve the strength of soil.

Based on the differences of microstructure between LFYRAS and C2, how the gels change microstructure and improve strength can be summarized. The main functions of the gels include coating, bonding, and filling. First of all, a small amount of produced gels attach themselves to soil particles as shown in Figure 6(a). Secondly, as the amount increases, enough gels can completely coat the soil particles. Of course, gels continuously fill the pores between particles while coating. Finally, as more pores are filled with gels, the coated particles are gradually bonded together firmly. The gels have great bonding strength and cohesion once they harden, so the bonding between coated particles is strong. The strong bonding makes the soil particles not easy to turn and slide when subjected to load, so the soil has higher strength.

To see the gels in C2 more clearly, SEM tests with larger magnification were performed, and the results are shown in Figures 6(c) and 6(d). It is known that the main product of cement hydration reaction is $\mathrm{CaO} \bullet \mathrm{SiO}_{2} \bullet \mathrm{YH}_{2} \mathrm{O}$ (abbreviated as C-S-H), which accounts for about $70 \%$. As evidence of hydration, lots of fibrous C-S-H (Figure 6(c)) and reticulate C-S-H (Figure 6(d)) can be found in C2. By analyzing the composition of cement and lime-fly ash, it can be known that both cement hydration and fly ash-lime reaction can produce C-S-H gels. However, by comparing Figures 6(a) and 6(b), it can be found that there are few gels in LF-YRAS, while there are many gels in $\mathrm{C} 2$. Therefore, it can be inferred that the main source of C-S-H gels in $\mathrm{C} 2$ is cement hydration at this early stage (curing for $7 \mathrm{~d}$ ).

3.3. EDS Test. The EDS test results are shown in Figure 7. In each SEM view, three test points are selected. The points are selected on gels attached to soil particles or gels between soil particles. On each point, an energy spectrum can be obtained. The function of Spectrum 2 and Spectrum 3 is to check the correctness and representativeness of Spectrum 1. In Figure 7, Spectrum 2 and Spectrum 3 are both nearly the same as Spectrum 1, which proves the representativeness of Spectrum 1. For brevity and clarity, Spectrum 2 and Spectrum 3 are not shown. Based on the EDS test results, the contents of different elements are shown in Figure 8.

Figure 7(a) shows the EDS result of LF-YRAS after $7 d$ standard curing. It can be seen from Figure 7(a) that gels in LF-YRAS mainly contain $\mathrm{O}, \mathrm{Al}, \mathrm{Si}, \mathrm{Ca}$, and other elements. Figure 7(b) shows the EDS result of C2 after $7 \mathrm{~d}$ standard curing. By comparing Figures 7(a) and 7(b), it can be found that the EDS results of LF-YRAS and C2 are similar. The gels in LF-YRAS and C2 have the same elements, while elements contents are different. This means that adding cement and hydration reaction of cement brings no new chemical element to LF-YRAS. 


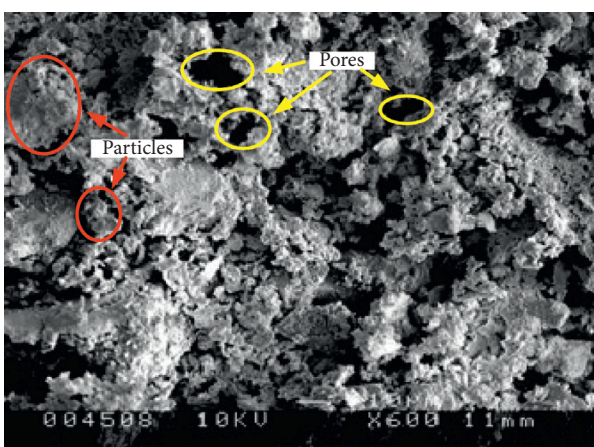

(a)

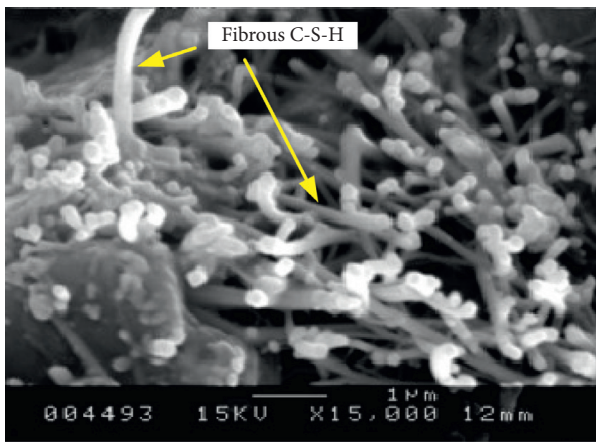

(c)

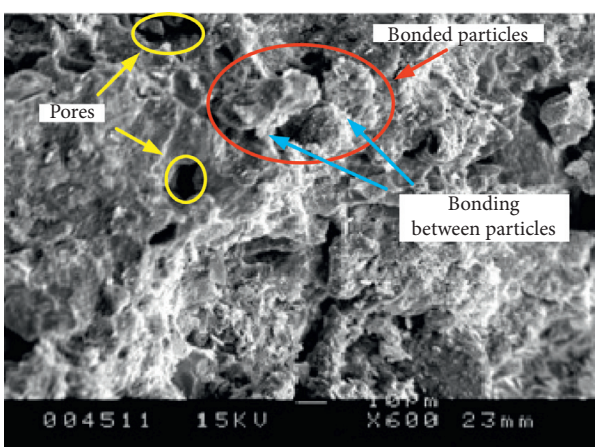

(b)

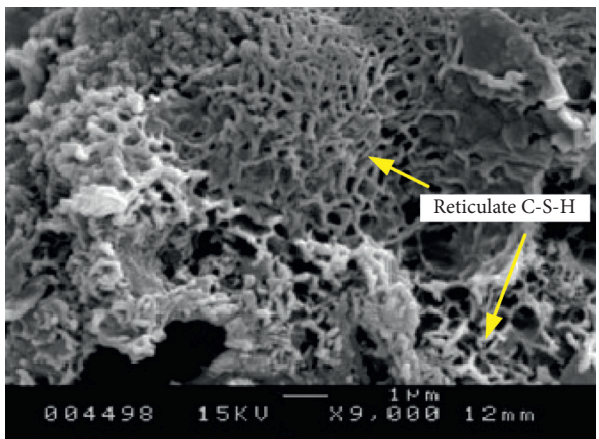

(d)

FiguRE 6: SEM test results of LF-YRAS and C2: (a) LF-YRAS, standard curing for $7 \mathrm{~d}, 1: 600$; (b) C2, standard curing for $7 \mathrm{~d}, 1: 600$; (c) C-S-H in C2, standard curing for $7 \mathrm{~d}, 1: 15000$; (d) C-S-H in C2, standard curing for $7 \mathrm{~d}, 1: 9000$.
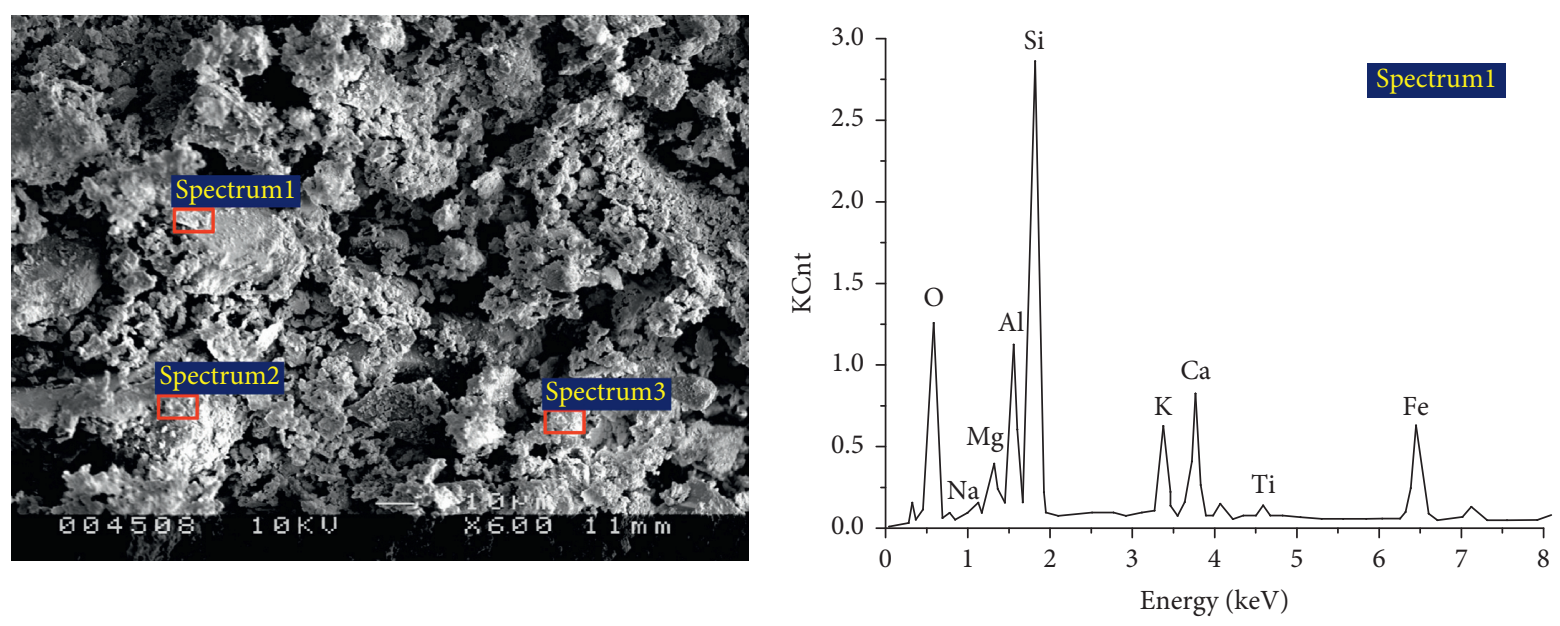

(a)

Figure 7: Continued. 

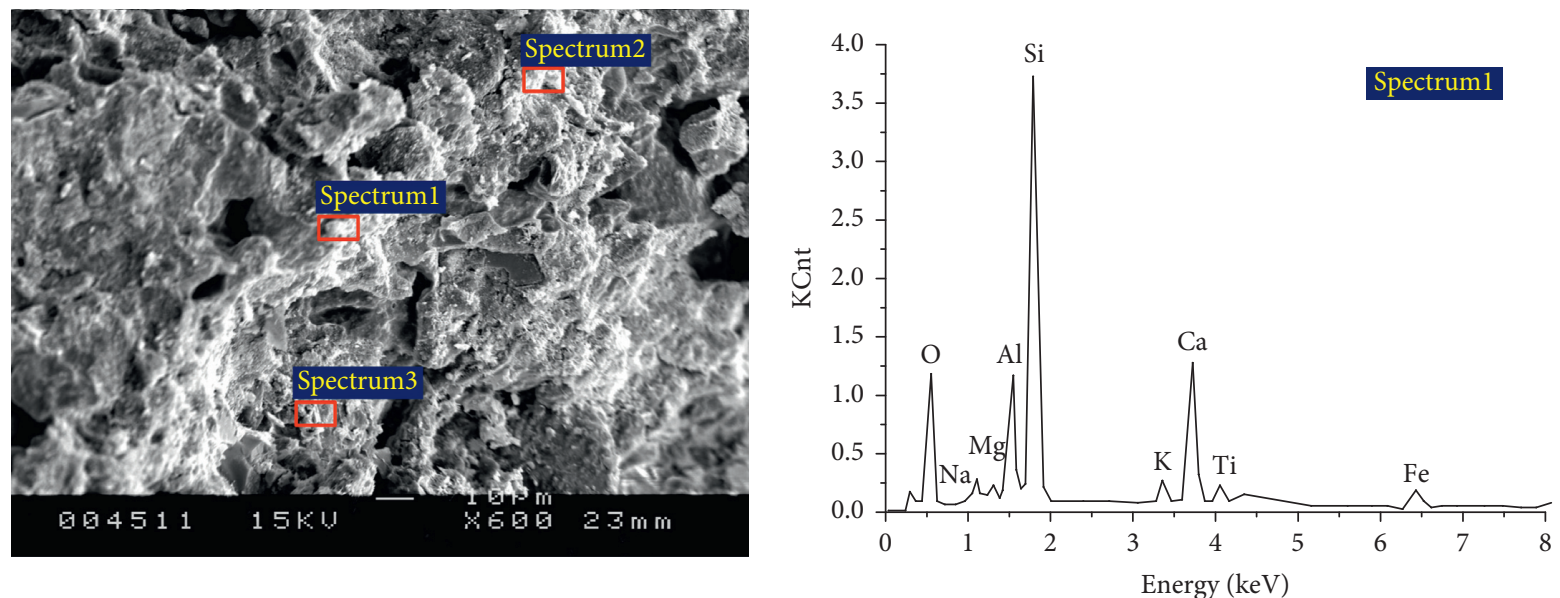

(b)
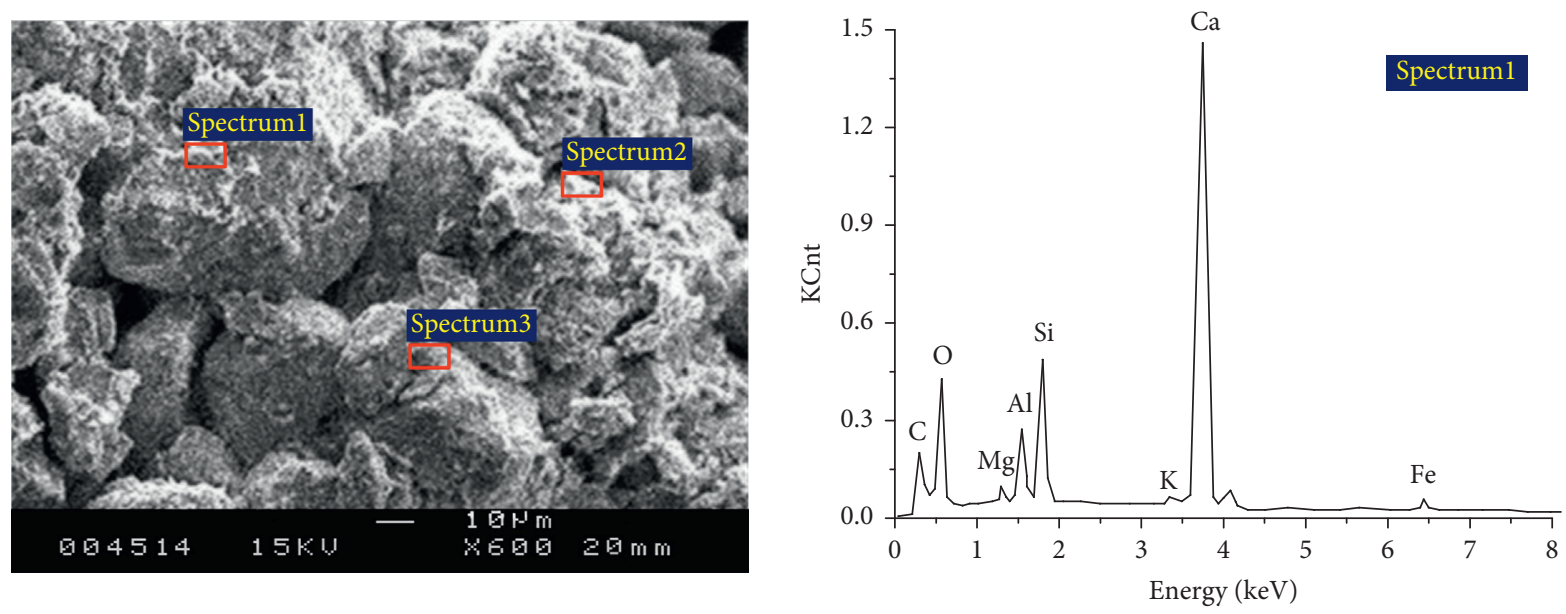

(c)

FIGURE 7: EDS test results of LF-YRAS and C2: (a) LF-YRAS, standard curing for $7 \mathrm{~d}$; (b) C2, standard curing for $7 \mathrm{~d}$; (c) C2, standard curing for $28 \mathrm{~d}$.

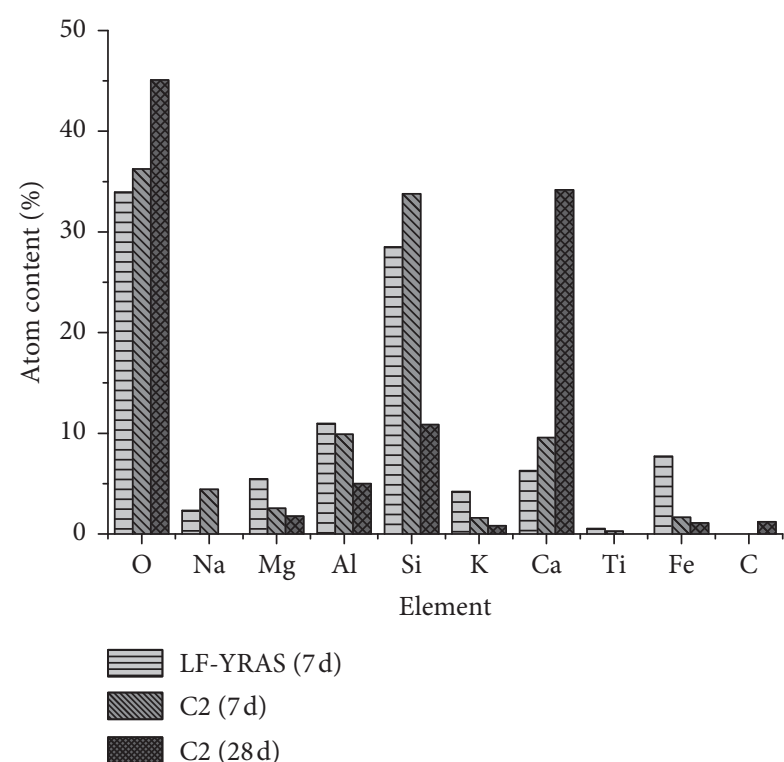

FIGURE 8: Element contents of gels in LF-YRAS (curing for $7 \mathrm{~d}$ ), C2 (curing for $7 \mathrm{~d}$ ), and $\mathrm{C} 2$ (curing for $28 \mathrm{~d}$ ).
Figure 7(c) shows the EDS result of C2 after $28 \mathrm{~d}$ standard curing. By comparing Figures $7(\mathrm{~b})$ and $7(\mathrm{c})$, it can be found that the type and content of elements in $\mathrm{C} 2$ have changed with the increase of curing time. The clearer changes are shown in Figure 8. It can be seen from Figure 8 that, with the increase of curing time, the changes of element in $\mathrm{C} 2$ include appearance of $\mathrm{C}$ (new element), significant increase of $\mathrm{Ca}$, increase of $\mathrm{O}$, decrease of $\mathrm{Mg}, \mathrm{Al}, \mathrm{Si}, \mathrm{K}$, and $\mathrm{Fe}$, and disappearance of $\mathrm{Na}$ and Ti. First, an important change is the appearance of $\mathrm{C}$, by which it can be predicted that carbonization occurs in $\mathrm{C} 2$. By analyzing the composition, it can be known that the source of carbonization is $\mathrm{Ca}(\mathrm{OH})_{2}$. As a product of carbonization, $\mathrm{CaCO}_{3}$ has the properties of being insoluble in water, high strength, and good water stability, which contributes to increasing soil strength. Second, another important change is the significant increase in $\mathrm{Ca}$. After curing for $7 \mathrm{~d}$, the atom content of $\mathrm{Ca}$ is $9.56 \%$, while after curing for $28 \mathrm{~d}$ the atom content increases to $34.18 \%$. The reason for the significant increase in Ca includes not only carbonization but also ion exchange. With the increase of $\mathrm{Ca}^{2+}$ in pore water, $\mathrm{Ca}^{2+}$ continuously exchanges with $\mathrm{Na}^{+}, \mathrm{K}^{+}$, and other ions attached to soil particles, which 
leads to the gradual increase of $\mathrm{Ca}^{2+}$ and a decrease of other ions on soil particles. After the replacement of univalent ion $\left(\mathrm{Na}^{+}\right.$and $\left.\mathrm{K}^{+}\right)$by divalent ion $\left(\mathrm{Ca}^{2+}\right)$, the thickness of bound water of soil particles becomes thinner, and thus, the spacing between soil particles becomes smaller, which reduces soil plasticity and increases soil strength. Finally, although the absolute amounts of $\mathrm{Mg}, \mathrm{Al}, \mathrm{Fe}$, and $\mathrm{Si}$ almost no change, their relative amounts (\%) must decrease as the absolute amounts of $\mathrm{O}$ and $\mathrm{Ca}$ increase significantly.

3.4. MIP Test. According to the relationship between injection pressure and injection amount in the MIP test, the cumulative pore volume percentage curve of stabilized YRAS is obtained, as shown in Figure 9. It can be seen from Figure 9 that the curves show a significant change at the point where the cumulative pore volume percentage equals $90 \%$, while the corresponding pore diameters at this point $\left(d_{90}\right)$ are different. The $d_{90}$ of LF-YRAS is $10-20 \mu \mathrm{m}$, while the $d_{90}$ of $\mathrm{C} 2$ is about $5 \mu \mathrm{m}$. In addition, it can be seen from Figure 9 that the curve of LF-YRAS is steeper and more biased to the right side than the curve of C2. Steeper curve means that LF-YRAS has more concentrated pore size distribution, and a curve more biased to the right side means LF-YRAS has more pores with larger size, which is consistent with the results of the SEM test.

Horpibulsuk classified the pores of stabilized soil into 5 types according to pore size, which includes pore with a size smaller than $0.01 \mu \mathrm{m}$ (pore in soil aggregate), pore with $0.01-0.1 \mu \mathrm{m}$ size (pore between soil aggregate), pore with $0.1-1 \mu \mathrm{m}$ size, pore with $1-10 \mu \mathrm{m}$ size, and pore with a size larger than $10 \mu \mathrm{m}[20,24]$. Referring to the method of Horpibulsuk, the pores of stabilized YRAS are classified, and the result is shown in Figure 10. It can be seen from Figure 10 that, in stabilized YRAS, the pores with $1-10 \mu \mathrm{m}$ size have the largest percentage: $54.45 \%$ in LF-YRAS (7 d), 61.1\% in C2 $(7 \mathrm{~d})$, and $47 \%$ in $\mathrm{C} 2(28 \mathrm{~d})$. In addition, it can be clearly found that LF-YRAS has more large pores than C2. In LFYRAS, the pores with a size larger than $10 \mu \mathrm{m}$ account for $37.17 \%$, whereas in C2 the pores with a size larger than $10 \mu \mathrm{m}$ only account for $9.64 \%$ (7d) and $11.27 \%$ (28 d), which is consistent with the qualitative analysis of the previous SEM test. Horpibulsuk believes that cement hydration products mainly fill pores with $0.1-10 \mu \mathrm{m}$ size [20], and Du believes that cement hydration products mainly fill pores with 1-10 $\mu \mathrm{m}$ size [56]. However, it can be seen from Figure 10 that, for stabilized YRAS, the cement hydration products mainly fill the pores with a size larger than $10 \mu \mathrm{m}$ at the early stage (before $7 \mathrm{~d}$ ) and fill the pores with $1-10 \mu \mathrm{m}$ size at the later stage $(7 \mathrm{~d}-28 \mathrm{~d})$. At the early stage (before $7 \mathrm{~d}$ ), the pores with a size larger than $10 \mu \mathrm{m}$ account for $37.17 \%$ in LFYRAS, while the percentage is reduced to $9.64 \%$ in $\mathrm{C} 2$. At the later stage ( $7 \mathrm{~d}-28 \mathrm{~d})$, the percentage of pores with $1-10 \mu \mathrm{m}$ size is reduced from $61.1 \%$ to $47 \%$ in C2.

In summary, the microscopic mechanism of cement improving the strength of LF-YRAS can be ascertained based on the test results of SEM, EDS, and MIP. At the early stage (before $7 \mathrm{~d}$ ), many gels (mainly C-S-H) are produced due to the rapid hydration reaction of cement, and the gels coat soil

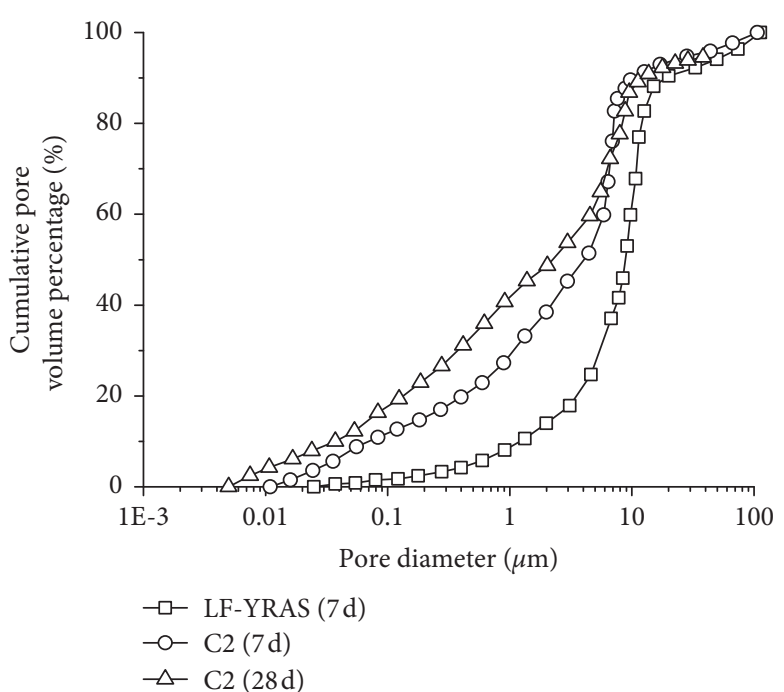

FIGURE 9: Cumulative pore volume percentage curve of LF-YRAS (curing for $7 \mathrm{~d}$ ), C2 (curing for $7 \mathrm{~d}$ ), and C2 (curing for $28 \mathrm{~d}$ ).

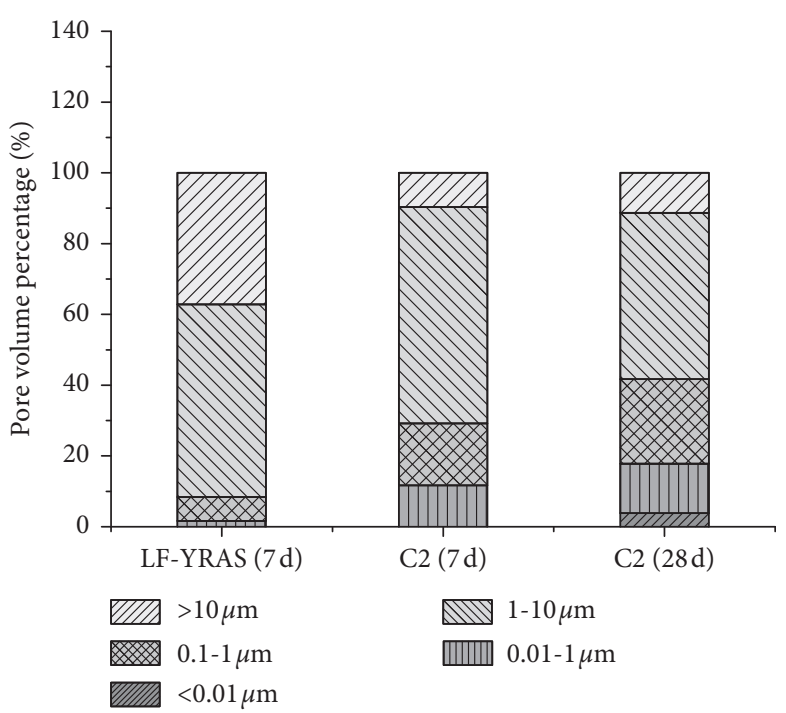

FIGURE 10: Pore classification and proportion of LF-YRAS (curing for $7 \mathrm{~d}$ ), C2 (curing for $7 \mathrm{~d}$ ), and C2 (curing for $28 \mathrm{~d}$ ).

particles, bond soil particles, and fill the pores between soil particles, which change the microstructure of LF-YRAS. The microstructure changes include large bonded particles, small number of pores, and dense particle arrangement. The percentage of pores with large size (larger than $10 \mu \mathrm{m}$ ) decreases from $37.17 \%$ to $9.64 \%$. These changes work together to help improve the early strength of LF-YRAS. At the later stage $(7 \mathrm{~d}-28 \mathrm{~d})$, with the increase of curing time, there are more hydration reactions and pozzolanic reactions in stabilized YRAS, which further changes soil microstructure. The percentage of pores with $1-10 \mu \mathrm{m}$ size is reduced from $61.1 \%$ to $47 \%$ in $\mathrm{C} 2$. In addition, carbonization and ion exchange occur in $\mathrm{C} 2$, which produces $\mathrm{CaCO}_{3}$ and thins bound water of soil particles. In a word, hydration reaction, pozzolanic reaction, carbonation, and ion exchange have 
worked together to improve the later strength of stabilized YRAS.

\section{Conclusions}

In this paper, the effect of cement on improving the strength of LF-YRAS and its microscopic mechanism has been experimentally studied. The main conclusions are listed as follows:

(1) LF-YRAS has low early UCS, which does not meet the requirements for subsequent construction. Adding cement can effectively improve the UCS of LF-YRAS, especially at the early stage. Meanwhile, cement can improve the water stability of LF-YRAS.

(2) For stabilized YRAS, there is a good linear correlation between normalized UCS and curing time, which can be used to predict the strength of different curing times based on the strength of $28 \mathrm{~d}$.

(3) After curing for $7 \mathrm{~d}$, LF-YRAS has the microscopic characteristics of small soil particles, large number of pores, and loose particle arrangement. Gels produced from cement hydration coat soil particles, bond soil particles, and fill the pores between soil particles, which change the microstructure of LFYRAS. The main changes include large bonded particles, small number of pores, and dense particle arrangement. The changes contribute to improving the early strength of LF-YRAS.

(4) With the increase of curing time, carbonation and ion exchange reaction occur in stabilized YRAS. The output of $\mathrm{CaCO}_{3}$ and the thinning of soil-bound water help to improve the later strength of soil.

(5) In stabilized YRAS, the pores with 1-10 $\mu \mathrm{m}$ size have the largest proportion. After adding cement, the proportion of pores with a size larger than $10 \mu \mathrm{m}$ has decreased significantly. Cement hydration products mainly fill the pores with a size larger than $10 \mu \mathrm{m}$ at the early stage (before $7 \mathrm{~d}$ ) and fill the pores with $1-10 \mu \mathrm{m}$ size at the later stage $(7 \mathrm{~d}-28 \mathrm{~d})$.

\section{Data Availability}

The data used to support the findings of this study are available from the corresponding author upon request.

\section{Conflicts of Interest}

The authors declare that there are no conflicts of interest regarding the publication of this paper.

\section{Acknowledgments}

The authors would like to thank Dr. Guanghua Cai and Dr. Shaoyun $\mathrm{Pu}$ for their suggestions on experiment, article writing, and revision. This research was funded by the National Natural Science Foundation of China (no. 40872173). The financial supports are gratefully acknowledged by the authors.

\section{References}

[1] ASTM D2487-17e1, Standard Practice for Classification of Soils for Engineering Purposes (Unified Soil Classification System), ASTM International, West Conshohocken, PA, USA, 2017.

[2] A. J. Puppala, J. A. Griffin, L. R. Hoyos, and S. Chomtid, "Studies on Sulfate-Resistant cement stabilization methods to address Sulfate-Induced soil heave," Journal of Geotechnical and Geoenvironmental Engineering, vol. 130, no. 4, pp. 391402, 2004.

[3] F. Sariosseiri and B. Muhunthan, "Effect of cement treatment on geotechnical properties of some Washington State soils," Engineering Geology, vol. 104, no. 1-2, pp. 119-125, 2009.

[4] S. Hebib and E. R. Farrell, "Some experiences on the stabilization of Irish peats," Canadian Geotechnical Journal, vol. 40, no. 1, pp. 107-120, 2003.

[5] S. R. Lo and S. P. Wardani, "Strength and dilatancy of a silt stabilized by a cement and fly ash mixture," Canadian Geotechnical Journal, vol. 39, no. 1, pp. 77-89, 2002.

[6] F. G. Bell, "Lime stabilization of clay minerals and soils," Engineering Geology, vol. 42, no. 4, pp. 223-237, 1996.

[7] S. Pu, Z. Zhu, H. Wang, W. Song, and R. Wei, "Mechanical characteristics and water stability of silt solidified by incorporating lime, lime and cement mixture, and SEU-2 binder," Construction and Building Materials, vol. 214, pp. 111-120, 2019.

[8] S. Dhar and M. Hussain, "The strength behaviour of limestabilised plastic fibre-reinforced clayey soil," Road Materials and Pavement Design, vol. 20, no. 8, pp. 1757-1778, 2018.

[9] S. Lee, M. Chung, H. M. Park, K. Song, and I. Chang, "Xanthan gum biopolymer as Soil-Stabilization binder for road construction using local soil in Sri Lanka," Journal of Materials in Civil Engineering, vol. 31, no. 11, p. 6019012, 2019.

[10] J. Shen, Y. Xu, J. Chen, and Y. Wang, "Study on the stabilization of a new type of waste solidifying agent for soft soil," Materials, vol. 12, no. 5, p. 826, 2019.

[11] A. A. Firoozi, C. Guney Olgun, A. A. Firoozi, and M. S. Baghini, "Fundamentals of soil stabilization," International Journal of Geo-Engineering, vol. 8, no. 1, 2017.

[12] S.-Y. Pu, Z.-D. Zhu, W.-L. Song, H.-R. Wang, and R.-J. Wei, "Deformation properties of silt solidified with a new SEU-2 binder," Construction and Building Materials, vol. 220, pp. 267-277, 2019.

[13] D. Wang, R. Zentar, N. E. Abriak, and W. Xu, "Shear strength behavior of Cement/Lime-Solidified dunkirk sediments by fall cone tests and vane shear tests," Geotechnical Testing Journal, vol. 36, no. 1, pp. 155-162, 2013.

[14] M. Türköz, H. Savaş, and G. Tasci, "The effect of silica fume and lime on geotechnical properties of a clay soil showing both swelling and dispersive features," Arabian Journal of Geosciences, vol. 11, no. 23, pp. 1-14, 2018.

[15] M. Turkoz and P. Vural, "The effects of cement and natural zeolite additives on problematic clay soils," Science and Engineering of Composite Materials, vol. 20, no. 4, pp. 395-405, 2013.

[16] D. Wang, N. E. Abriak, and R. Zentar, "Stress-Dependent behavior of artificially structured and reconstituted marine soils," International Journal of Geomechanics, vol. 17, pp. 4016101-4016103, 2017.

[17] D. Wang and L. Korkiala-Tanttu, "1-D compressibility behaviour of cement-lime stabilized soft clays," European Journal of Environmental and Civil Engineering, vol. 24, pp. 1-19, 2020. 
[18] S. Horpibulsuk, N. Miura, and T. S. Nagaraj, "Assessment of strength development in cement-admixed high water content clays with Abrams' law as a basis," Géotechnique, vol. 53, no. 4, pp. 439-444, 2003.

[19] S. Paria and P. K. Yuet, "Solidification-stabilization of organic and inorganic contaminants using portland cement: a literature review," Environmental Reviews, vol. 14, no. 4, pp. 217-255, 2006.

[20] S. Horpibulsuk, R. Rachan, A. Chinkulkijniwat, Y. Raksachon, and A. Suddeepong, "Analysis of strength development in cement-stabilized silty clay from microstructural considerations," Construction and Building Materials, vol. 24, no. 10, pp. 2011-2021, 2010.

[21] B. Le Runigo, O. Cuisinier, Y. J. Cui, V. Ferber, and D. Deneele, "Impact of initial state on the fabric and permeability of a lime-treated silt under long-term leaching," Canadian Geotechnical Journal, vol. 46, no. 11, pp. 1243-1257, 2009.

[22] G. Cai, S. Liu, Y. Du, D. Zhang, and X. Zheng, "Strength and deformation characteristics of carbonated reactive magnesia treated silt soil," Journal of Central South University, vol. 22, no. 5, pp. 1859-1868, 2015.

[23] G. H. Cai, Y. J. Du, S. Y. Liu, and D. N. Singh, "Physical properties, electrical resistivity, and strength characteristics of carbonated silty soil admixed with reactive magnesia," $\mathrm{Ca}$ nadian Geotechnical Journal, vol. 52, no. 11, pp. 1699-1713, 2015.

[24] S. Horpibulsuk, R. Rachan, and Y. Raksachon, "Role of fly ash on strength and microstructure development in blended cement stabilized silty clay," Soils and Foundations, vol. 49, no. 1, pp. 85-98, 2009.

[25] R. Jauberthie, F. Rendell, D. Rangeard, and L. Molez, "Stabilisation of estuarine silt with lime and/or cement," Applied Clay Science, vol. 50, no. 3, pp. 395-400, 2010.

[26] J. R. Zhang and X. Cao, "Stabilization of expansive soil by lime and fly ash," Journal of Wuhan University of TechnologyMaterials Science Edition, vol. 17, no. 4, pp. 73-77, 2002.

[27] S. Deka, S. K. Dash, and S. Sreedeep, "Strength of LimeTreated fly ash using bentonite," Geotechnical Engineering, vol. 46, no. 3SI, pp. 73-81, 2015.

[28] A. Cheshomi, A. Eshaghi, and J. Hassanpour, "Effect of lime and fly ash on swelling percentage and Atterberg limits of sulfate-bearing clay," Applied Clay Science, vol. 135, pp. 190-198, 2017.

[29] J. H. Beeghly, "Recent experiences with lime-fly ash stabilization of pavement subgrade soils, base, and recycled asphalt," in Proceedings of the International Ash Utilization Symposium, Center for Applied Energy Research, pp. 1-18, University of Kentucky, Frankfort, KY, USA, 2003.

[30] S. G. Bai and Y. F. Hou, "Study on properties of cement limefly-ash soil," Key Engineering Materials, vol. 302-303, pp. 457-461, 2006.

[31] P. V. Sivapullaiah, J. P. Prashanth, and A. Sridharan, "Optimum lime content for fly ashes and the role of the curing period," Journal of Testing and Evaluation, vol. 28, no. 6, pp. 499-506, 2000.

[32] Z. Shen, Y. Cao, and L. Fang, "Experimental investigation of rapid stabilization of soft clay soils using chemical admixtures," Soil Mechanics and Foundation Engineering, vol. 54, no. 3, pp. 202-210, 2017.

[33] G. Vinoth, S. Moon, J. Moon, and T. Ku, "Early strength development in cement-treated sand using low-carbon rapidhardening cements," Soils and Foundations, vol. 58, no. 5, pp. 1200-1211, 2018.
[34] M. Oualmakran, B. C. N. Mercatoris, and B. François, "Poresize distribution of a compacted silty soil after compaction, saturation, and loading," Canadian Geotechnical Journal, vol. 53, no. 12, pp. 1902-1909, 2016.

[35] L. Miao, S. L. Houston, Y. Cui, and J. Yuan, "Relationship between soil structure and mechanical behavior for an expansive unsaturated clay," Canadian Geotechnical Journal, vol. 44, no. 2, pp. 126-137, 2007.

[36] D. C Sekhar and S. Nayak, "SEM and XRD investigations on lithomargic clay stabilized using granulated blast furnace slag and cement," International Journal of Geotechnical Engineering, vol. 13, no. 6, pp. 615-629, 2017.

[37] Y. Xi, X. Wu, and H. Xiong, "Solidification/Stabilization of pb-contaminated soils with cement and other additives," Soil and Sediment Contamination: An International Journal, vol. 23, no. 8, pp. 887-898, 2014.

[38] $\mathrm{H}$. Wu and $\mathrm{L}$. Hu, "Microfabric change of electro-osmotic stabilized bentonite," Applied Clay Science, vol. 101, pp. 503-509, 2014.

[39] L. Wang, A. Roy, R. K. Seals, and Z. Byerly, "Suppression of sulfate attack on a stabilized soil," Journal of the American Ceramic Society, vol. 88, no. 6, pp. 1600-1606, 2005.

[40] K. Kaewmanee, P. Krammart, T. Sumranwanich, P. Choktaweekarn, and S. Tangtermsirikul, "Effect of free lime content on properties of cement-fly ash mixtures," Construction and Building Materials, vol. 38, pp. 829-836, 2013.

[41] Y. Yi, K. Lu, S. Liu, and A. Al-Tabbaa, "Property changes of reactive magnesia-stabilized soil subjected to forced carbonation," Canadian Geotechnical Journal, vol. 53, no. 2, pp. 314-325, 2016.

[42] W.-Y. Xia, Y.-S. Feng, F. Jin, L.-M. Zhang, and Y.-J. Du, "Stabilization and solidification of a heavy metal contaminated site soil using a hydroxyapatite based binder," Construction and Building Materials, vol. 156, pp. 199-207, 2017.

[43] İ. Bozbey, "Microfabric evaluation of Lime-Treated clays by mercury intrusion porosimetry and environment scanning electron microscopy," International Journal of Civil Engineering, vol. 16, no. 4, pp. 443-456, 2018.

[44] M. Lee and J. Jeon, "Study for the stabilization of arsenic in the farmland soil by using steel making slag and limestone," Economic and Environmental Geology, vol. 43, no. 4, pp. 305-314, 2010.

[45] J. E. Lim, J. K. Sung, B. Sarkaret et al., "Impact of natural and calcined starfish (Asterina pectinifera) on the stabilization of $\mathrm{Pb}, \mathrm{Zn}$ and as in contaminated agricultural soil," Environmental Geochemistry and Health, vol. 39, no. 2, pp. 431-441, 2017.

[46] M. Jaiswal and B. Lal, "Stabilization of clayey soil with garlic skin and rice husk ash for flexible pavement construction," Geotechnical Testing Journal, vol. 40, no. 6, p. 20160227, 2017.

[47] H.-L. Wu, F. Jin, Y.-L. Bo, Y.-J. Du, and J.-X. Zheng, "Leaching and microstructural properties of lead contaminated kaolin stabilized by GGBS-MgO in semi-dynamic leaching tests," Construction and Building Materials, vol. 172, pp. 626-634, 2018.

[48] Ministry of Transport of the People's Republic of China, Test Methods of Soils for Highway Engineering, China Communications Press, Beijing, China, (In Chinese), 2007.

[49] Ministry of Transport of the People's Republic of China, Test Methods of Materials Stabilized with Inorganic Binders for Highway Engineering, China Communications Press, Beijing, China, (In Chinese), 2009.

[50] General Administration of Quality Supervision, Inspection and Quarantine of the People's Republic of China and 
Standardization Administration of China, Portland Cement for Road, Standards Press of China, Beijing, China, (In Chinese), 2017.

[51] M. Türköz, "Delayed compaction effect on the strength and dynamic properties of clay treated with lime," Geomechanics and Engineering, vol. 18, no. 5, pp. 471-480, 2019.

[52] D. Wang, R. Zentar, and N. E. Abriak, "Temperatureaccelerated strength development in stabilised marine soils as road construction materials," Journal of Materials in Civil Engineering, vol. 29, no. 5, 2017.

[53] General Administration of Quality Supervision, Inspection and Quarantine of the People's Republic of China and Standardization Administration of China, General Rules for Measurement of Length in Micron Scale by SEM, Standards Press of China, Beijing, China, (In Chinese), 2008.

[54] General Administration of Quality Supervision, Inspection and Quarantine of the People's Republic of China and Standardization Administration of China, Microbeam AnalysisQuantitative Analysis Using Energy Dispersive Spectrometry, The Commercial Press, Beijing, China, (In Chinese), 2012.

[55] General Administration of Quality Supervision, Inspection and Quarantine of the People's Republic of China and Standardization Administration of China, Pore Size Distribution and Porosity of Solid Materials by Mercury Porosimetry and Gas Adsorption-Part 1: Mercury Porosimetry, Standards Press of China, Beijing, China, (In Chinese), 2008.

[56] Y. Du, N. Jiang, L. Wang, and M. Wei, "Strength and microstructure characteristics of cement-based solidified/stabilized zinc-contaminated kaolin," Chinese Journal of Geotechnical Engineering, vol. 11, pp. 2114-2120, 2012. 